\title{
Enduring motor memory of walking on a split-belt treadmill in young children and adults
}

\author{
Brittany Lissinna ${ }^{1}$, Allison Smith ${ }^{1}$, Kaylie La ${ }^{1}$, Jaynie F Yang ${ }^{1,2^{*}}$ \\ ${ }^{1}$ Department of Physical Therapy, ${ }^{2}$ Neuroscience and Mental Health Institute, University of \\ Alberta, Edmonton, AB, Canada
}

*Corresponding author:

Email: jaynie@ualberta.ca

Email address of other authors:

lissinna@ualberta.ca

atsmith1@ualberta.ca

kla@ualberta.ca

Short title: Memory of split-belt walking across age groups

Declaration of interests: none

\section{Acknowledgements}

This project was partially funded by the Natural Sciences and Engineering Research Council of Canada, grant number 2011-138181 to JFY. Funding to BL was provided by the Women and Children's Health Research Institute summer research studentship, Alberta Innovates Health Solutions summer studentship, and NSERC Undergraduate Student Research Award over several time periods. We thank Drs Kristin Musselman and Erin Vasudevan for helpful comments on earlier versions of this manuscript. We thank Dr Ming Ye for assistance with statistical modeling and testing, and Dr Jacques Bobet for programing assistance with preparing the figures.

Abstract word count: 252

Manuscript word count: 2899 


\section{Abstract}

Background: Adults and children modify their motor program to accommodate persistent changes in movement conditions, called motor adaptation. We studied motor adaptation using a split-belt treadmill, with the belts for each leg at different speeds. A memory trace is reflected when reintroduction of the previously novel condition results in a smaller initial error in comparison to the first exposure. To date, retention of motor adaptation on a split-belt treadmill is only known for a 24 hour period.

Research question: We wondered if retention of split-belt adaptation extends over days and weeks, and whether it varies as a function of age.

Methods: We studied the persistence of the memory trace over 24 hours, one week, and two weeks, in young children (3-6 yr old), younger adults (20-30 yr old) and older adults (50-70 yr old).

Results: We found that retention of the memory trace declines with the interval duration, but was evident up to 2 weeks after initial exposure in all age groups. Retention of the motor memory in children and younger adults was better than older adults. Further, only older adults demonstrated forgetting between trials on a single day when a short break was introduced, but this forgetting was diminished with repeated trials.

Significance: The results indicate that long term memory of motor adaptation is affected by age, but it may be possible to enhance the memory in older adults by repeated exposure. For clinical practice, this may mean that older adults need more repetition when learning walking-related motor skills.

Keywords: motor adaptation, locomotion, human 


\section{Introduction}

Motor memory from skills mastered during childhood, such as riding a bicycle, endure a lifetime, even when the skills are rarely re-experienced in adulthood. In contrast, new motor learning is less enduring in older adults, such as with sequence learning in a serial reaction time test (1-3), visuomotor tracking (4), and in a ballistic task (5).

Motor adaptation, a form of motor learning that modifies a well learned motor program to persistent changes in the environment (6), is also affected by age. Children adapt at a slower rate than younger adults (7-9), which may confer children with better retention (10). Older compared to younger adults had more variable adaptation rates (11-17). Interestingly, the slower rate of adaptation in older adults has been linked to a decline in cognitive resources (17, 18), and reduced volume in the striatum, prefrontal and sensorimotor cortical areas (19).

Motor adaptation involves a number of memory processes, including modification of an internal model (20), and other model-free processes $(21,22)$. Memory of motor adaptation has been quantified in two ways - retention and savings. Retention is defined as a smaller movement error when exposed to a previously learned adaptation $(23,24)$, while savings is a faster rate of relearning after a period of washout (25). Interestingly, retention is evident by the age of 6 years, whereas savings is not seen until 12 years (26). Savings, but not retention, has also been linked to 'model free' mechanisms of motor memory $(21,22)$.

Here, we focus on age-related retention of split-belt adaptation over days and weeks, in young children, younger and older adults. Long-term retention of motor adaptation has not been documented, and is relevant to its usefulness in motor rehabilitation (27). We used the splitbelt paradigm, because it is a novel task for adults and children alike, and it is not dependent on visual acuity or muscle strength, both of which may vary with age. 


\section{MATERIALS AND METHODS}

\section{Participants}

Participants had no known health problems that would interfere with motor learning, and were naïve to split-belt walking. Children (3-6 yo), young adults (20-30 yo) and older adults (50-70 yo) were recruited. We chose young children because their slow time course of learning may offer an advantage for retention (24), young adults because their adaptation is well known, and older adults because there is evidence for within-session forgetting (17). The small age range for children was to minimize the variability associated with development (9). Adult participants and a parent/guardian of children gave informed, written consent. Verbal assent was obtained from the children at the time of the experiments. The Health Research Ethics Board, University of Alberta, approved the study (Pro00043622). There was no prior information regarding possible differences between groups. Thus, sample size was based on a prior publication of agerelated differences in split-belt walking (9).

\section{Experimental Protocol}

Participants were tested on 2 days, separated by 24 hours, 1 week or 2 weeks (Figure 1). The allocation of participants to intervals was partly determined by participant availability, but was otherwise random. On Day 1, two tied-belt trials (belts at the same speed) were followed by 5 split-belt trials (speed ratio 2:1) (Figure 1). Trials were $3 \mathrm{~min}$, separated by a 1 min standing break. The trial length was to accommodate children, who were more amenable to multiple short bouts rather than continuous walking. Because some adults exhibit surprise when first exposed to split-belt walking, resulting in an exaggerated initial error (25), a 'surprise' trial of no more than 5 seconds was inserted between the two tied-belt trials (25). Children do not display 'surprise', so this was not inserted for them $(8,9)$. On Day 2, participants started with 5 split- 
belt trials to determine their retention of the adaptation, followed by 2 tied-belt trials to quantify the aftereffect.

A Woodway split-belt treadmill (Woodway USA Inc., Waukesha, WI) was used. Adults used a tied-belt speed of $0.7 \mathrm{~m} / \mathrm{s}$, and split-belt speeds of $1.4 \mathrm{~m} / \mathrm{s}$ and $0.7 \mathrm{~m} / \mathrm{s}$. The speed of the tiedbelt trials was set according to leg length for children, with the distance from the greater trochanter to the lateral malleolus (meters) providing the speed in meters/s (9); the speed ratio was 2:1 for the split-belt trials. The leg on the fast belt was chosen randomly on the first day, and then held constant for subsequent measures.

For safety, all participants held a front handrail and an adult spotter stood behind the children. All participants watched a movie of their choice during walked. Adults were instructed not to think about their walking, while children were asked questions about the movie to divert their attention from walking.

\section{Instrumentation}

Infrared emitting markers (Northern Digital Inc., Waterloo, ON) were positioned bilaterally at the top of the pelvis directly above the hip, the greater trochanter, the knee joint line, the lateral malleolus, and the head of the $5^{\text {th }}$ metatarsal. Two 3-D Investigator motion sensors on each side of the treadmill captured the positions of the markers using NDI First Principles software. In addition, all trials were recorded with a video camera for quality control. A timer synchronized the video image with the marker data.

\section{Data Analysis}

Video recordings were used to exclude steps in which the participant was not stepping with one foot on each belt. We focused on step length symmetry, because step length is a global 
measure of spatial and temporal adaptation on the split-belt treadmill (9). Custom MatLab (The Mathworks Inc., Natick, MA) code was used to analyze the data. Step length was defined as the antero-posterior distance between the ankle markers of each leg at the time of heel strike of the slow $\left(\mathrm{SL}_{s}\right)$ and fast $\left(\mathrm{SL}_{\mathrm{f}}\right)$ leg, respectively. Step symmetry $(\mathrm{SS})$ was the normalized difference between the fast and slow step length:

$S S=\frac{S L_{f}-S L_{S}}{S L_{f}+S L_{S}}$

A negative step symmetry means the slow step was longer than the fast step. Participant data were smoothed using epochs of 9-step averages, arbitrarily chosen as a compromise between the fast and slow time courses of learning in adults and children, respectively. The data were then averaged across participants within each age group and time gap.

Since 3 to 6 years old children do not always show adaptation (9), we first determined if there was evidence of adaptation in each child. A standard t-test was used for Day 1 data to determine if the average step symmetry of the last split-belt trial was significantly more positive than the first split-belt trial $(p<0.05)$. The same test was used on the adult trials for comparison. In addition, presence of an after-effect on Day 2 was confirmed by the average step symmetry of the first 10 steps on the tied-belt being more positive than the last 30 steps on the split-belt (standard t-test). If both of the above comparisons showed no differences, indicating absence of learning, the child was removed from further analysis.

The differences in the time course of adaptation on Day 1 between the age groups were determined by collapsing the data across the 3 gap durations for each age group. This was justified since there were no significant differences in age between the participants with different gap periods. 
Step symmetry during specific times were of interest. Baseline symmetry was the average from all steps in the second tied-belt trial on Day 1, reflecting walking symmetry prior to the split-belt trials. The initial error on the split-belt for Day $1\left(\mathrm{IE}_{1}\right)$ was the average of the first 9 steps on the split-belt. The final error on Day $1\left(\mathrm{FE}_{1}\right)$ was the average of the last 30 steps on the split-belt (25). Initial error on Day $2\left(\mathrm{IE}_{2}\right)$ was the average of the first 9 steps on the split-belt. Forgetting between Day 1 to Day 2 was the difference between the initial error on Day 2 and the final error on Day 1, with negative values indicating forgetting (Forgetting $\left.=I E_{2}-F E_{1}\right)$. The aftereffect $\left(A E_{2}\right)$ was the average of the first 9 steps of the tied-belt on Day 2 immediately following the split-belt trials.

Forgetting between trials on Day 1 was the difference between the average of the 9 steps just before and just after a break. Only the adults were considered in this comparison, as the variability in children is likely to mask any real differences between trials.

\section{Statistical Analysis}

One-way ANOVAs were used to compare the ages between participant groups within the same gap interval. Because there were no age differences within each age group, the time course of adaption on Day 1 was collapsed across different gap durations within each age group. This data were then modeled by a mixed, linear regression model to compare participants in the different age groups using the log likelihood ratio test. In addition, we used the Akaike Information Criteria (28) to determine if a linear or exponential model provided a better fit of the time course for each age group.

Two-way ANOVAs (factors: age group and gap interval) determined the differences between the groups in: 1) baseline stepping symmetry, 2) initial error when first exposed to the split-belt $\left(\mathrm{IE}_{1}\right), 3$ ) after-effect (AE) in Day 2, and 4) forgetting between Day 1 and Day 2. 
Within-day forgetting for Day 1 was compared between the younger adults and older adults using a mixed model ANOVA (between-subject factor: age group, and within-subject factor: breaks). Within-day forgetting for Day 2 was analyzed in the same way. A significant difference was set at $\mathrm{p}<0.1$ for all comparisons to avoid Type II errors with the small number of participants per group.

\section{Results}

Seventy-four volunteers ( 31 children, 21 younger adults, 22 older adults) participated in the study. Data from one child were eliminated from analysis because of an absences of motor adaption. See Table 1 for participant numbers, sex and age in each group.

All participants completed the trials except for one child, who did not want to continue after 4 split-belt trials on Day 1; this same child completed all trials on Day 2. This child's data was included for analysis.

\section{Similarities between the groups}

The age of the participants within each age group were not different from each other (Table 2, Age). Symmetry of walking with tied-belts on Day 1 was the same for all 9 groups (Table 2, Baseline step symmetry). Initial error on the split-belt on Day 1 was the same between groups (Table 2, SB Initial error), indicating all groups were equally perturbed by the split-belt.

\section{Time course of adaptation and overall learning}

The time course of adaptation during split-belt walking on Day 1 for each age groups shows the effect of age on the initial adaptation (Figure 2). The time course is truncated at the lowest number of total steps obtained (i.e., the number of steps from the child who completed 4 instead of 5 split-belt trials). All groups showed a reduction in step asymmetry over time, with 
the children showing a slower time course and more variability compared to the adults. The best fitting model for all age groups was a linear model. The age groups were significantly different from each other, with children being different from younger adults [log ratio(LR) chi2 $(62)=462.65$, prob $=0.0000]$ and older adults $[$ LR chi2(62)=180.36, prob=0.0000], but younger and older adults were not different from each other [LR Chi2(62)=-282.29, prob=1.000]. The aftereffect on Day 2, a reflection of overall learning over the two days, was the same across all age groups and time gaps (Table 2, Day 2, Aftereffect).

\section{Forgetting between Day 1 and Day 2}

The time course of split-belt adaptation is superimposed for each of the groups on Day 1 and Day 2 in Figure 3. All groups showed evidence of retention on Day 2, as reflected by the starting steps on Day 2 (orange) being less asymmetric than the starting steps on Day 1 (blue). The smaller initial error on Day 2 led to all groups achieving symmetric walking sooner on Day 2 compared to Day 1. The forgetting between days is shown in bar graph form (Figure 3, bar graph),

Statistical tests of forgetting were not significantly different for the age $\mathrm{x}$ gap interaction (Table 2, Forgetting, Day 1 to Day 2). Thus, 1-way ANOVAs were used to examine the main effect of age collapsed across gap durations, and main effect of gap duration collapsed across age. Only a significant effect for age was observed (Table 2, Forgetting, Day 1 to Day 2).

\section{Forgetting between trials within a day}

Data from younger and older adults of different gap durations on Day 1 were combined to examine the effect of age, since Day 1 was the same for everyone. Figure 4 shows the step symmetry before and after each break, together with the initial 9 steps on the split-belt. Statistical comparison of the forgetting within Day 1, represented by the difference between the 
average of the 9 steps immediately after a break minus the average of the 9 steps immediately before the break, showed older adults forgot significantly more than the younger adults (mixed model ANOVA with repeated-measures over breaks, and between-subject factor of age). There was no interaction, but a significant main effect of age (Table 2, Forgetting, Within Day 1). Posthoc test using one-way repeated measures ANOVA for each age group indicated the older adults showed a significant effect of breaks, whereas the younger adults did not (Table 2, Forgetting, Within Day 1, post-hoc). Further pairwise comparisons for the older adults using paired t-tests indicated the differences were between the first break and all the others $(p=0.052,0.023,0.023$, for Break 1 vs Breaks 2, 3 and 4, respectively), whereas Break 2 through 4 were not different from each other ( $p=0.857,0.140,0.171$, for Breaks 2 vs 3,2 vs 4 and 3 vs 4 , respectively). Forgetting between trials was not examined for Day 2 because of the low statistical power resulting from the smaller number of participants in each group.

\section{DISCUSSION}

The novel findings are retention remains strong for children and younger adults after a 1- and 2week interval from the first exposure, whereas older adults had forgotten significantly more. Further, within the first day of split-belt adaptation, older adults forgot more than younger adults between trials, but this within-day forgetting was short-lived, and only evident between the first and second trial on Day 1. Contrary to our original expectation, young children were no better than younger adults at retention, at least up to a 2-week interval after first exposure.

\section{Characteristics of adaptation in children}

The rate of adaptation on Day 1 was considerably slower in children compared to adults, confirming previous reports for split-belt adaptation $(8,9)$ and other forms of adaptation (7). The slower time course of split-belt adaptation may be related to the absence of a 'cognitive 
component' of learning, seen in adults $(21,22)$, since the fast time course of split-belt adaptation can be interfered with by a concurrent cognitive task, especially in older adults (17). Further, the fact that young children did not exhibit 'savings' 24 hours later (26) is also consistent with an immature cognitive component of motor learning, since savings in other forms of adaptation may result from a cognitive process of motor selection or retrieval $(22,29)$.

\section{Endurance of the memory in all age groups}

There was a trend for the greatest difference in memory between age groups to appear at 1week after initial exposure (Figure 3, bar graph). By 2 weeks, all groups have forgotten a considerable amount, but still far from completely forgotten. We estimated the proportion of forgetting by dividing the average initial asymmetry on the split-belt on Day 2 by the average initial error on the split-belt treadmill on Day 1. Average forgetting at 2 weeks was $42 \%, 52 \%$ and $67 \%$ for children, younger and older adults, respectively.

\section{Forgetting in older adults}

The forgetting in older adults within the first day of exposure confirms the earlier findings of Malone and Bastian (17) that older adults forget between trials on the first day of exposure. Some procedural differences between the two studies include the duration of each split-belt trial, and the rest period between trials, both of which were considerably shorter in our study. Thus, instead of five 3-min split-belt trials with 1 min rest between trials here, Malone and Bastian used three 5 -min trials with 5 min rest between trials. With the short rest between trials and more repeated trials in our study, forgetting was only evident between the first and second trials in older adults, whereas it was evident between both rest periods in the earlier study. This suggests that with repeated exposure and shorter breaks, older adults may be able to retain the learning better. Indeed, retention of split-belt adaptation in adult participants 
after stroke, over 12 sessions of repeated practice, has shown about half of the participants can retain the learning, resulting in their over ground walking becoming more symmetric (27). Many of the participants in that study were over 50 years old, and whether a participant responded to the intervention did not appear to be age-related, although the number of participants was small. Overall, repeated practice may be one way to improve retention in older adults.

Limited evidence suggests acute, aerobic exercise may enhance subsequent motor learning and memory in persons with stroke (30) and Parkinson's disease (31). Finally, neuromodulation with non-invasive brain stimulation may also hold promise for improving certain types of motor adaptation in older adults (32), but its influence on motor memory remains to be seen.

\section{Conflict of interest statement}

All authors disclose no conflicts. 


\section{Tables}

Table 1. Participant numbers and ages from each experimental groups.

\begin{tabular}{|c|c|c|c|c|}
\hline \multicolumn{2}{|c|}{ Gap duration } & \multirow{2}{*}{$\frac{24 \text { hours }}{12(6)}$} & \multirow{2}{*}{$\frac{1 \text { week }}{9(3)}$} & \multirow{2}{*}{$\frac{2 \text { weeks }}{9(3)}$} \\
\hline Kids & $N(f)$ & & & \\
\hline & Age (yr) & $4.6 \pm 0.9$ & $4.9 \pm 0.9$ & $4.4 \pm 0.5$ \\
\hline Young & $N(f)$ & $7(4)$ & $7(2)$ & $7(4)$ \\
\hline adults & Age (yr) & $23.5 \pm 3.7$ & $24.0 \pm 2.0$ & $25.6 \pm 2.3$ \\
\hline Old & $N(f)$ & $7(4)$ & $8(6)$ & $7(4)$ \\
\hline adults & Age (yr) & $62.1 \pm 8.6$ & $59.7 \pm 5.7$ & $59.7 \pm 7.1$ \\
\hline
\end{tabular}

$\mathrm{N}$ is the number of participants contributing data in the group with the number of female ( $\mathrm{f}$ ) participants in parentheses. Age is represented by years (yr) with mean \pm 1 SD.

\section{Table 2. Statistical results.}

\begin{tabular}{|c|c|c|c|}
\hline Measure & Statistic & Results & Post-hoc \\
\hline Age & 1-way ANOVA & $\begin{array}{l}\text { Gap: } F=0.891, p=0.422 \\
\text { (children) } \\
\text { Gap: } F=1.110, p=0.351(Y A) \\
\text { Gap: } F=0.267, p=0.769(\mathrm{OA})\end{array}$ & \\
\hline $\begin{array}{c}\text { Baseline step } \\
\text { symmetry }\end{array}$ & 2-way ANOVA & $\begin{array}{l}\text { Age: } F=0.92, p=0.274 \\
\text { Gap: } 0.462, p=0.632 \\
\text { Interaction: } 1.314, p=0.274\end{array}$ & \\
\hline
\end{tabular}

Day 1

$\begin{array}{lll} & & \text { Age: } F=0.243, p=0.785 \\ \text { SB Initial error } \quad \text { 2-way ANOVA } & \text { Gap: } F=0.731, p=0.485 \\ & \text { Interaction: } F=1.326, p=0.270\end{array}$

Day 2

\begin{tabular}{lcll} 
Aftereffect & 2-way ANOVA & $\begin{array}{l}\text { Age: } F=1.186, p=0.312 \\
\text { Gap: } F=1.472, p=0.237 \\
\text { Interaction: } F=1.550, p=0.198\end{array}$ \\
\hline Forgetting & & & \\
Day 1 to Day 2 & 2-way ANOVA & $\begin{array}{l}\text { Age: } F=2.357, p=0.103 \\
\text { Gap: } F=0.203, p=0.817\end{array}$ & $\begin{array}{l}\text { 1-way main effect age: } \\
F=2.645, p=0.078 *\end{array}$
\end{tabular}


Interaction: $F=0.543, p=0.705 \quad$ 1-way main effect gap:

$\mathrm{F}=0.280, \mathrm{p}=0.757$

Within Day $1 \quad$ Mixed model
ANOVA

Age: $F=2.978, p=0.092 *$

1-way RM ANOVA:

Interaction: $F=1.964, p=0.123$

$Y A: F=0.311, p=0.817$

OA: $F=4.524, p=0.006^{*}$

The results from all statistical comparisons are listed here. The measures included: Age measured in years, Baseline step symmetry was the average of step symmetry (see equation in MATERIALS and METHODS, Data Analysis) from all steps in the second tied-belt trial on Day 1. SB Initial error was the average of the first 9 steps of split-belt walking on Day 1 . Aftereffect was the average of the first 9 steps of tied-belt walking on Day 2. Day 1 to Day 2 Forgetting was the difference in step symmetry between the first 9 steps of split-belt walking on Day 2 minus the SB Final error on Day 1. Within Day Forgetting was the difference in step symmetry between the first 9 steps after a break minus the last 9 steps before the break. 


\section{Figures}

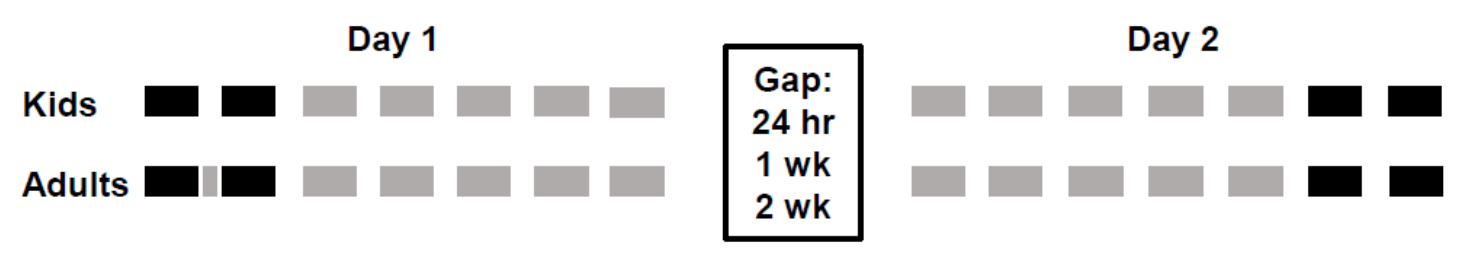

Figure 1. Experimental sequence. Each walking trial is represented by the solid horizontal bars. Black bars represent tied-belt trials and gray represent split-belt trials. All trials were 3 min long except the surprise trial of 5 strides, 5 seconds long, short gray bar between 2 tiedbelt trials on Day 1. All participants experienced the same sequence of trials, with the exception of the surprise trial for adults only. Three gap durations between Day 1 and Day 2 were used for each of the age groups.

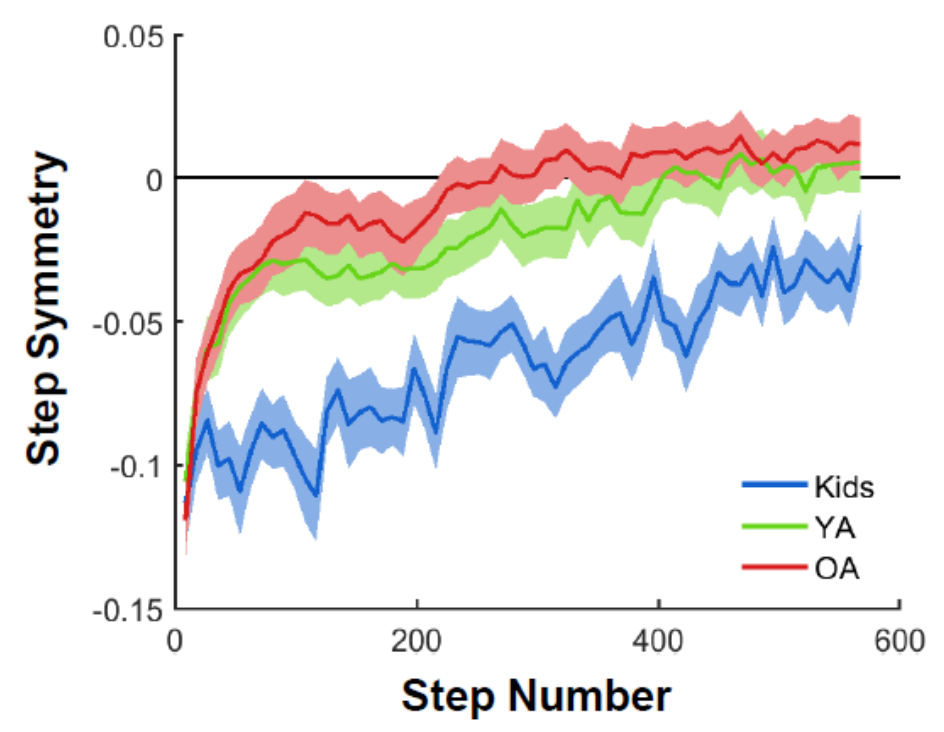

Figure 2. Time course of split-belt adaptation on Day 1. Average (9-step average) step symmetry is shown for the 3 age groups over the adaptation period of $\sim 15 \mathrm{~min}$. The age groups each contain data from $n=30$ for young children (Kids), $n=21$ for younger adults (YA), and $n=22$ for older adults (OA). 


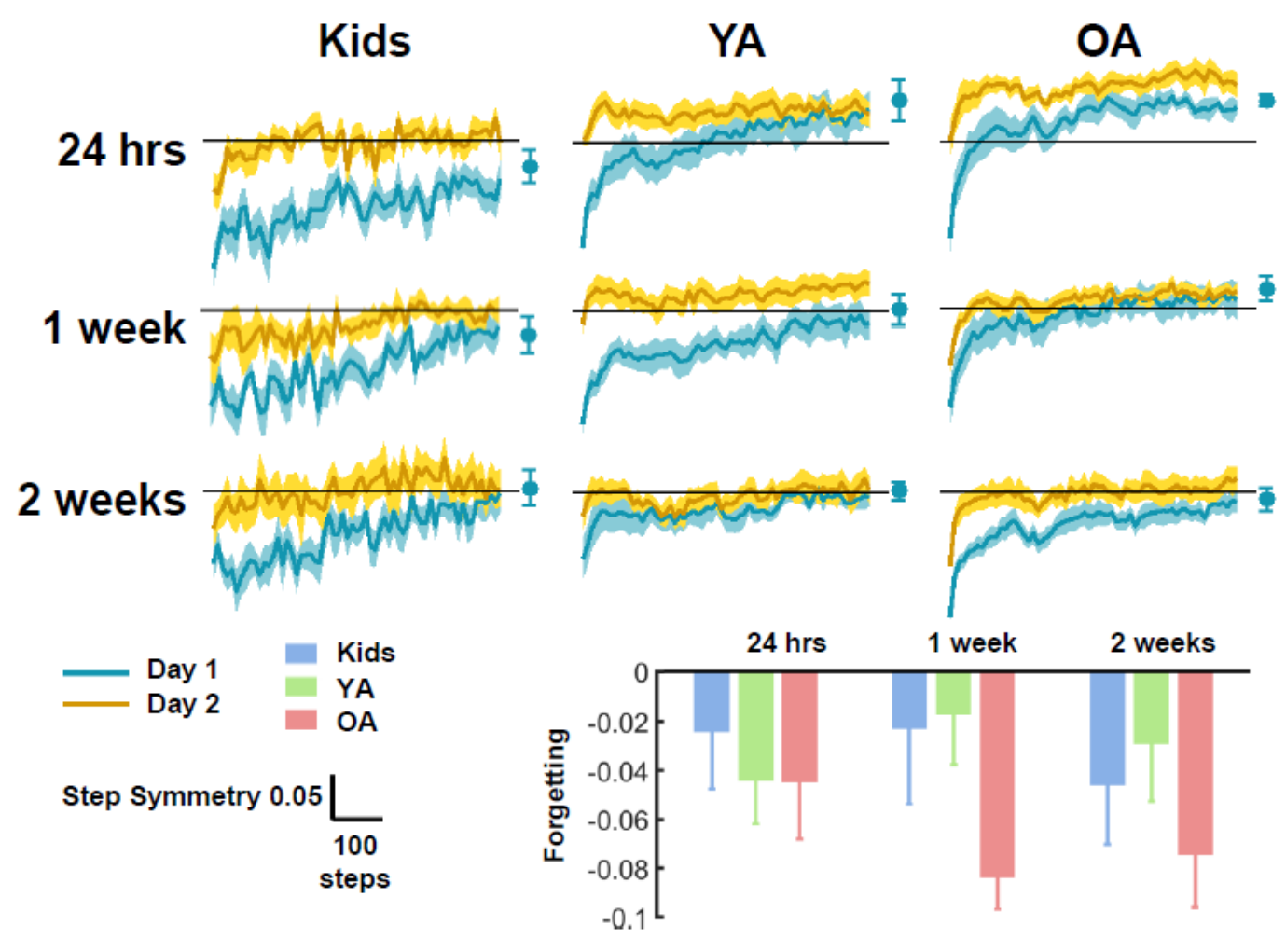

Figure 3. Average split-belt adaptation on Day 1 and Day 2 for each age group and gap durations. Adaptation is shown for 9 step averages across 567 steps, with the final step symmetry on Day 1 (average of last 30 steps, final error) shown as a blue symbol with \pm 1 SEM. The bar graph (bottom) shows the forgetting between the Initial Error on Day 2 minus the Final Error on Day 1. Means and 1 SEM are shown. Older adults (OA) showed more forgetting compared to the younger age groups (Kids and younger adults - YA). Abbreviations: Kids children 3-6 y.o.; YA - younger adults, OA - older adults. 

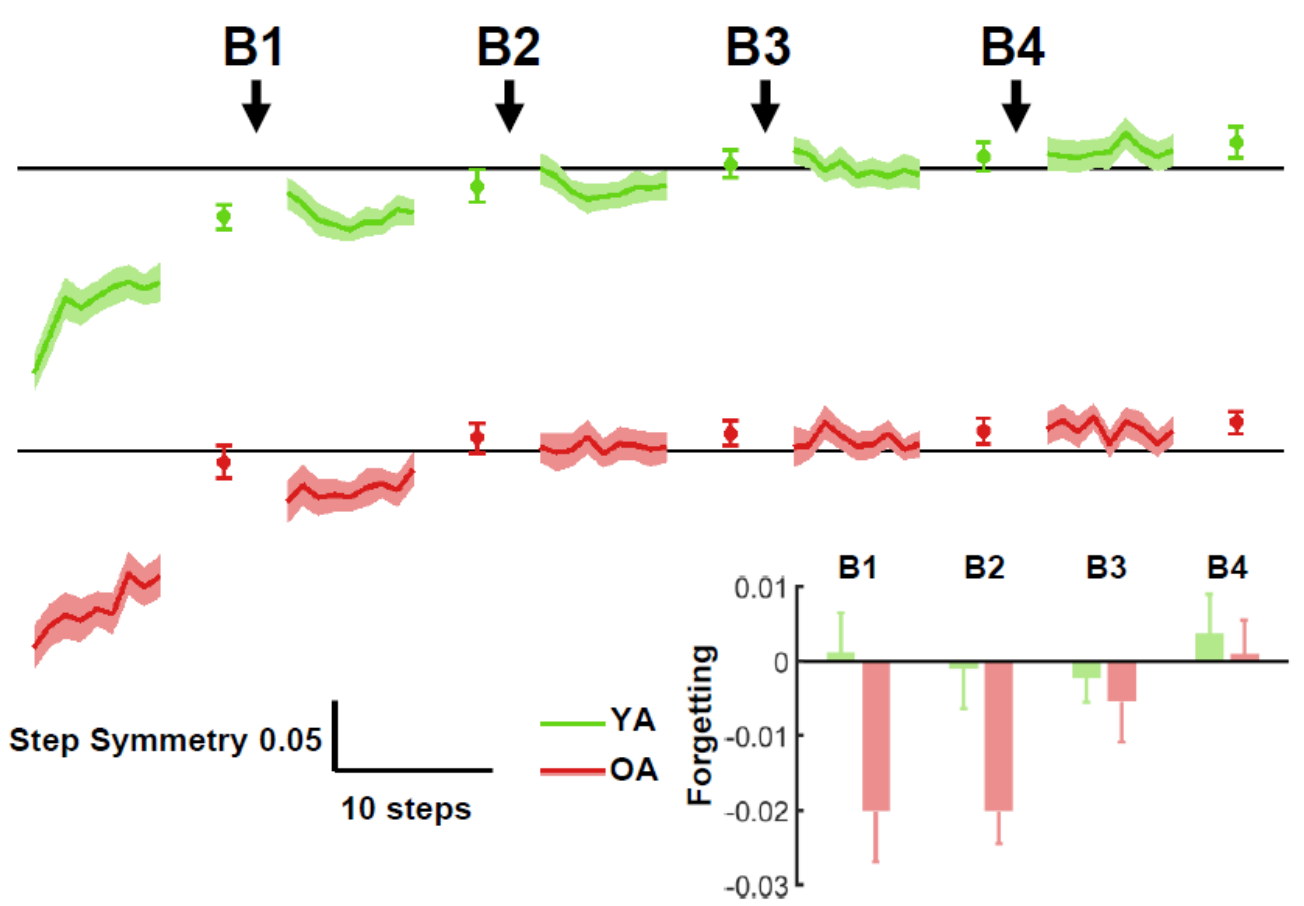

Figure 4. Forgetting between trials on Day 1. The step-by-step average step symmetry for each age group is shown for the first 9 steps on the split-belt treadmill, then the overall average of the last 9 steps before the breaks (B) and the step-by-step average of the first 9 steps right after the breaks, averaged across participants in each adult age group. The bar graph represents the quantified difference in forgetting between trials (forgetting = average of first 9 steps after break - average of last 9 steps before break). YA- younger adults, OA older adults. 


\section{References}

1. Brown RM, Robertson EM, Press DZ. Sequence skill acquisition and off-line learning in normal aging. PLoS One. 2009;4(8):e6683.

2. Nemeth $D$, Janacsek K. The dynamics of implicit skill consolidation in young and elderly adults. J Gerontol B Psychol Sci Soc Sci. 2011;66(1):15-22.

3. Spencer RM, Gouw AM, Ivry RB. Age-related decline of sleep-dependent consolidation. Learn Mem. 2007;14(7):480-4.

4. Rodrigue KM, Kennedy KM, Raz N. Aging and longitudinal change in perceptualmotor skill acquisition in healthy adults. J Gerontol B Psychol Sci Soc Sci. 2005;60(4):P174-81.

5. Roig M, Ritterband-Rosenbaum A, Lundbye-Jensen J, Nielsen JB. Aging increases the susceptibility to motor memory interference and reduces off-line gains in motor skill learning. Neurobiol Aging. 2014;35(8):1892-900.

6. Martin TA, Keating JG, Goodkin HP, Bastian AJ, Thach WT. Throwing while looking through prisms. II. Specificity and storage of multiple gaze-throw calibrations. Brain. 1996;119 ( Pt 4):1199-211.

7. Konczak J, Jansen-Osmann P, Kalveram KT. Development of force adaptation during childhood. J Mot Behav. 2003;35(1):41-52.

8. Musselman KE, Patrick SK, Vasudevan EV, Bastian AJ, Yang JF. Unique characteristics of motor adaptation during walking in young children. J Neurophysiol. 2011;105(5):2195-203.

9. Vasudevan EV, Torres-Oviedo G, Morton SM, Yang JF, Bastian AJ. Younger is not always better: development of locomotor adaptation from childhood to adulthood. J Neurosci. 2011;31(8):3055-65.

10. Smith MA, Ghazizadeh A, Shadmehr R. Interacting adaptive processes with different timescales underlie short-term motor learning. PLoS Biol. 2006;4(6):e179.

11. Fernandez-Ruiz J, Hall C, Vergara P, Diiaz R. Prism adaptation in normal aging: slower adaptation rate and larger aftereffect. Brain Res Cogn Brain Res. 2000;9(3):223-6. 12. Buch ER, Young S, Contreras-Vidal JL. Visuomotor adaptation in normal aging. Learn Mem. 2003;10(1):55-63.

13. Vandevoorde K, Orban de Xivry JJ. Internal model recalibration does not deteriorate with age while motor adaptation does. Neurobiol Aging. 2019;80:138-53. 14. Trewartha KM, Garcia A, Wolpert DM, Flanagan JR. Fast but fleeting: adaptive motor learning processes associated with aging and cognitive decline. J Neurosci. 2014;34(40):13411-21.

15. Huang HJ, Ahmed AA. Older adults learn less, but still reduce metabolic cost, during motor adaptation. J Neurophysiol. 2014;111(1):135-44.

16. Bruijn SM, Van Impe A, Duysens J, Swinnen SP. Split-belt walking: adaptation differences between young and older adults. J Neurophysiol. 2012;108(4):1149-57.

17. Malone LA, Bastian AJ. Age-related forgetting in locomotor adaptation. Neurobiol Learn Mem. 2016;128:1-6. 
18. Conradsson D, Hinton DC, Paquette C. The effects of dual-tasking on temporal gait adaptation and de-adaptation to the split-belt treadmill in older adults. Exp Gerontol. 2019;125:110655.

19. Wolpe N, Ingram JN, Tsvetanov KA, Henson RN, Wolpert DM, Cam CAN, et al. Age-related reduction in motor adaptation: brain structural correlates and the role of explicit memory. Neurobiol Aging. 2020;90:13-23.

20. Wolpert DM, Miall RC, Kawato M. Internal models in the cerebellum. Trends Cogn Sci. 1998;2(9):338-47.

21. Huang VS, Haith A, Mazzoni P, Krakauer JW. Rethinking motor learning and savings in adaptation paradigms: model-free memory for successful actions combines with internal models. Neuron. 2011;70(4):787-801.

22. Morehead JR, Qasim SE, Crossley MJ, Ivry R. Savings upon Re-Aiming in Visuomotor Adaptation. J Neurosci. 2015;35(42):14386-96.

23. Brashers-Krug T, Shadmehr R, Bizzi E. Consolidation in human motor memory. Nature. 1996;382(6588):252-5.

24. Joiner WM, Smith MA. Long-term retention explained by a model of short-term learning in the adaptive control of reaching. J Neurophysiol. 2008;100(5):2948-55. 25. Malone LA, Vasudevan EV, Bastian AJ. Motor adaptation training for faster relearning. J Neurosci. 2011;31(42):15136-43.

26. Musselman KE, Roemmich RT, Garrett B, Bastian AJ. Motor learning in childhood reveals distinct mechanisms for memory retention and re-learning. Learn Mem. 2016;23(5):229-37.

27. Reisman DS, McLean H, Keller J, Danks KA, Bastian AJ. Repeated split-belt treadmill training improves poststroke step length asymmetry. Neurorehabil Neural Repair. 2013;27(5):460-8.

28. Akaike H. New Look at Statistical-Model Identification. leee T Automat Contr. 1974;Ac19(6):716-23.

29. Huberdeau DM, Haith AM, Krakauer JW. Formation of a long-term memory for visuomotor adaptation following only a few trials of practice. J Neurophysiol. 2015;114(2):969-77.

30. Siengsukon CF, Boyd LA. Sleep enhances implicit motor skill learning in individuals poststroke. Top Stroke Rehabil. 2008;15(1):1-12.

31. Steib S, Wanner P, Adler W, Winkler J, Klucken J, Pfeifer K. A Single Bout of Aerobic Exercise Improves Motor Skill Consolidation in Parkinson's Disease. Front Aging Neurosci. 2018;10:328.

32. Hardwick RM, Celnik PA. Cerebellar direct current stimulation enhances motor learning in older adults. Neurobiol Aging. 2014;35(10):2217-21. 